\title{
Epidemiology of hoarding disorder
}

Ashley E. Nordsletten, Abraham Reichenberg, Stephani L. Hatch,

Lorena Fernández de la Cruz, Alberto Pertusa, Matthew Hotopf and David Mataix-Cols

\section{Background}

Hoarding disorder is typified by persistent difficulties discarding possessions, resulting in significant clutter that obstructs the individual's living environment and produces considerable functional impairment. The prevalence of hoarding disorder, as defined in DSM-5, is currently unknown.

\section{Aims}

To provide a prevalence estimate specific to DSM-5 hoarding disorder and to delineate the demographic, behavioural and health features that characterise individuals with the disorder.

\section{Method}

We conducted a two-wave epidemiological study of 1698 adult individuals, originally recruited via the South East London Community Health (SELCOH) study. Participants screening positively for hoarding difficulties in wave 1 , and who agreed to be re-contacted for wave $2(n=99)$, underwent in-home psychiatric interviews and completed a battery of self-report questionnaires. Current DSM-5 diagnoses were made via consensus diagnostic procedure.

\section{Results}

In total, 19 individuals met DSM-5 criteria for hoarding disorder at the time of interview, corresponding to a weighted prevalence of $1.5 \%(95 \% \mathrm{Cl}$ 0.7-2.2). Those with hoarding disorder were older and more often unmarried (67\%). Members of this group were also more likely to be impaired by a current physical health condition (52.6\%) or comorbid mental disorder (58\%), and to claim benefits as a result of these issues (47.4\%). Individuals with hoarding disorder were also more likely to report lifetime use of mental health services, although access in the past year was less frequent.

\section{Conclusions}

With a lower-bound prevalence of approximately $1.5 \%$, hoarding disorder presents as a condition that affects people of both genders and is associated with substantial adversity.

\section{Declaration of interest}

None.
Hoarding disorder, a new disorder in DSM- $5,{ }^{1}$ is characterised by a persistent reluctance to discard objects, resulting in severely obstructed living spaces, distress, impairment and, often, adverse repercussion both for the sufferer ${ }^{2,3}$ and for those around this individual. $^{4,5}$

Despite advancements in the literature, much remains unknown about the basic epidemiology of hoarding disorder. Although such information is essential for mapping the health services required by this population, only a handful of studies have attempted to approach hoarding disorder from an epidemiological perspective. Taken together, these works have estimated the behaviour's prevalence to be between 2 and $6 \% .^{6-8}$ Such figures give a sense that hoarding is a relatively common psychiatric problem, however the broad range of estimates hints at the methodological issues and inconsistencies that have characterised work to date.

The most apparent of these methodological issues concerns the variable approaches studies have employed to define hoarding caseness. Often relying on remotely gathered (e.g. out of home) or self-report measures to establish key hoarding symptoms, these assessments have offered limited consideration of the alternative conditions (e.g. obsessive-compulsive disorder, OCD) and features (e.g. the role of third parties) which may affect, account for, or obscure hoarding activity. And although research suggests that home visits and clinical interviews represent essential tools for the assessment of hoarding disorder - permitting a first-hand assessment of clutter severity and a nuanced evaluation of hoarding activity - few studies have incorporated these direct assessments into their methodology. ${ }^{1,9,10}$

In light of these significant limitations, it is tenable that the current approximations of hoarding prevalence represent an overestimation or mischaracterisation of the true hoarding disorder population. The current study sought to provide more accurate estimates of hoarding disorder and its associated characteristics and comorbidities in an ethnically diverse, representative, community sample. In addition, this work sought to provide a delineation of the demographic, behavioural and health features which characterise individuals diagnosed with hoarding disorder.

\section{Method}

\section{Study design and participants}

Participants were initially recruited, and their demographic and health features assessed, as part of the South East London Community Health (SELCoH) study: a two-stage, large-scale, community-based epidemiological survey assessing the health outcomes of an ethnically and socioeconomically diverse segment of London. Recruitment for stage 1 (hereafter SELCoH-I), was done between 2008 and 2010, with the final data-set containing information on 1698 adults, aged between 16 and 90 years, garnered from 1075 randomly selected households across two London boroughs. Individuals were eligible for participation providing they lived in a household in the catchment area. No further exclusion criteria applied and, where necessary due to language limitations, interpreters were provided. Further details on SELCoH's organisation, sample and procedures may be found elsewhere. ${ }^{11}$

Following conclusion of SELCoH-I, a second phase (hereafter SELCoH-II) was launched in 2011. Several substudies have been hosted under this ongoing project and data for the current investigation was derived from one such study (hereafter Hoarding Study). Contributors were all SELCoH-I participants who consented to be contacted for SELCoH-II and who responded (positively or negatively) to the following screening question (administered during SELCoH-I): 'During your lifetime, have you ever accumulated so many things that your home was very cluttered (to the extent that you could not use some rooms for 
their intended purpose) and you found it very difficult to discard or give away these items?' Following omission of two invalid assessments, the final sample of responders totalled 1587 participants (56.5\% female), aged 16-90 years (median 37). A subset of this population, consisting of all individuals who responded 'yes' to the screening question, was targeted for diagnostic interview in the current investigation (Fig. 1).

\section{Procedures}

For SELCoH-II, a process of staggered re-recruitment was initiated in September 2011. At this time, individuals providing recontact consent $(n=1589)$ were prioritised - principally by the date of their SELCoH-I interviews - to ensure a comparable lapse of time between the collection of baseline and follow-up data. A maximum of four contact attempts (inclusive of any messages and/or home visits) were permitted per eligible individual. Where contact was achieved, potential participants were given study information, reminded that their continued engagement was voluntary and, where possible, scheduled for an in-home interview.

Participants in the Hoarding Study were recruited secondarily from all individuals engaging with SELCoH-II. Those eligible for participation in the Hoarding Study (e.g. those who endorsed the screening question; $n=191$ ) were given information on study aims and procedures at the close of their SELCoH-II interview. Those interested were invited to complete the Hoarding Study during the same interview session or, if preferred, a separate meeting was scheduled. Informed consent was obtained from all participants.

Trained interviewers carried out each Hoarding Study assessment in pairs, in person and, primarily, in participants' homes $(96 \%)$. Interviews were done in alternative locations on three occasions, due either to relocation or discomfort completing the study in the living environment. Clutter was assessed via photographs in these cases. ${ }^{12}$ Each interview, regardless of location, lasted 15-30 min. In addition, each participant was asked to complete a set of self-report questionnaires. Participants received $\mathfrak{E} 5 \quad(\sim \$ 8)$ for their time. The King's College London Research Ethics Committee approved the study (reference PNM/ 10/11-106).

\section{Diagnostic procedures}

The main interviewer (responsible for 56\% of assessments) received extensive training in diagnosing hoarding disorder as part of the London Field Trial. ${ }^{1}$ The remaining five interviewers were comprehensively trained by the research team, including a series of trial sessions led by the main interviewer. All diagnoses were determined via consensus meetings using a best estimate procedure. $^{13}$

Initially, the research team - which included the primary rater (A.E.N.) and two experienced researchers (L.F.C. and D.M-C.) reviewed all available evidence from the interviews, questionnaires and other information sources, and reached a consensus regarding the presence/absence of hoarding disorder and the endorsement of each individual criterion/specifier. Additionally, a consultant psychiatrist with expertise in hoarding disorder (A.P.), who was not involved in the initial assessments or consensus meetings, was masked to and reviewed all materials and arrived at his own diagnostic decisions. Discrepancies between these ratings $(n=4$; $4 \%$ of the interviewed sample) were subsequently reviewed by the research team and a final consensus diagnosis determined. At the conclusion of this procedure, participants were assigned to one of the following groups: hoarding disorder (all criteria met), subclinical (diagnosis withheld owing to insufficient clutter and/or distress; all other criteria met) or no hoarding disorder.

\section{Measures}

\section{Hoarding Study measures}

Clinician-administered. Participants were screened for OCD using the relevant module of the Mini International Neuropsychiatric Interview (MINI). ${ }^{14,15}$ The current presence of hoarding disorder was then determined using the Structured Interview for Hoarding Disorder (SIHD), a semi-structured interview that contains questions mirroring each diagnostic criterion required for hoarding disorder assessment. ${ }^{16}$ Through a series of skip rules, the SIHD also assists clinicians in ruling out general medical or DSM-5 conditions that can cause hoarding behaviour $^{1}$ and enables the assessment of the disorder's specifiers. Prior work indicates that diagnoses made using the SIHD have excellent interrater reliability $(\kappa=0.87-0.97)$, and a high degree of both sensitivity (0.98) and specificity (1). ${ }^{1}$ In our sample, the degree of clutter was also further quantified via the Clutter Image Rating (CIR). ${ }^{17}$

Self-administered. Participants self-rated their symptom severity using the Hoarding Rating Scale Self-Report (HRS-SR). ${ }^{18}$ To examine beliefs underlying acquisition behaviour, the Compulsive Acquisition Scale was also completed. ${ }^{19}$ Finally, the Home Environment Index $(\mathrm{HEI})^{20}$ was used to evaluate the level of squalor in participants' accommodation.

\section{SELCOH-I measures}

Comprehensive details on the SELCoH-I measures are provided elsewhere. ${ }^{11}$ Briefly, demographic features including gender, ethnicity, educational attainment, relationship and employment status were assessed at initial interview and treated categorically. Continuous variables included age and number of rooms (sum of all rooms in each participant's home, excluding kitchen and bathrooms). Informal notes regarding the state of the participant's home environments (recorded during SELCoH-I) were also examined for indications of hoarding behaviour (e.g. significant clutter), to offer a test of the sensitivity and temporal stability of hoarding disorder diagnoses.

Perceived general health was rated via the following item from the Short Form Health Survey (SF-12): ${ }^{21}$ 'In general, would you say your health is: excellent/very good, good or fair/poor?' Functional impairment, as a result of mental or physical health, was considered present if occupational/social activity was compromised throughout the past month. Body mass index was calculated using height and weight derived during initial interview.

Alcohol consumption was examined via the Alcohol Use Disorders Identification Test (AUDIT), ${ }^{22}$ using a conventional cut-off point of $\geqslant 8$ to define hazardous alcohol use. ${ }^{11,23}$ Smoking was treated categorically with participants characterised as 'never', 'past', 'current' or 'occasional' smokers. Drug use over the past year and/or lifetime was marked present if participants reported using one or more of the following: cannabis, cocaine, ecstasy, amphetamines, tranquilisers, lysergic acid diethylamide (LSD), crack or heroin.

The revised Clinical Interview Schedule $(\mathrm{CIS}-\mathrm{R})^{24}$ was used to assess the presence of common mental disorders. This fully structured instrument has been developed to assist non-clinicians with common mental disorder evaluation in community settings, with a score of $\geqslant 12$ traditionally used to indicate their presence. Through the use of a specialised algorithm, the CIS-R also 
provides ICD- $10^{25}$ diagnoses for disorders, including major depression, generalised anxiety disorder and OCD.

Psychotic features were examined using the Psychosis Screening Questionnaire (PSQ). ${ }^{26}$ The PSQ hypomania question ('Over the past year, have there been times when you felt very happy without a break for days on end?') as well as its probe ('Did people around you think it was strange or complain about it?') were used to evaluate manic features. The PSQ is not a diagnostic instrument and increasing scores are interpreted as indicating an increased risk for, rather than a diagnosis of, the associated conditions.

Additional measures included the Standardised Assessment of Personality Abbreviated Scale (SAPAS), ${ }^{27}$ the Chalder Fatigue Questionnaire, ${ }^{28}$ the 15-item Patient Health Questionnaire (PHQ-15) ${ }^{29}$ and the Primary Care Posttraumatic Stress Disorder screener (PC-PTSD). ${ }^{30}$ Results from the SAPAS, the Chalder Fatigue Questionnaire and the PC-PTSD were treated categorically, with respective cut-off points of 3, 4 and 3 used to identify personality dysfunction, clinical fatigue and PTSD. ${ }^{31}$ The PHQ-15 is reported continuously, with increasing scores reflecting increasing severity of somatic symptoms.

The utilisation of mental healthcare services was evaluated both for the past year and over the participant's lifetime. Utilisation was considered endorsed if an individual reported speaking with a general practitioner, family doctor, therapist/ counsellor or other source about a mental, nervous or emotional problem during either (or both) of these time periods.

\section{Statistical analyses and weighting procedures}

Analyses were conducted using STATA version 11. Comparisons across groups for demographic, physical, and mental health variables were completed using chi-squared tests for categorical variables and Wilcoxon rank sum tests for continuous variables. For categorical analyses with cell values below 5, Fisher's exact tests were used. As the purpose of these comparisons was merely to describe the current sample, results from these comparisons are reported unweighted with $95 \%$ confidence intervals (CIs).

When computing the prevalence estimates, weights were introduced to account for household clustering, non-response at initial recruitment and 'missingness' at all subsequent (postSELCoH-I) recruitment stages. ${ }^{11}$ As, in the current study, those electing not to participate were older, more often White and experiencing fewer health issues than those who engaged, the 'weighted prevalence' estimates also corrected for these potential biases.

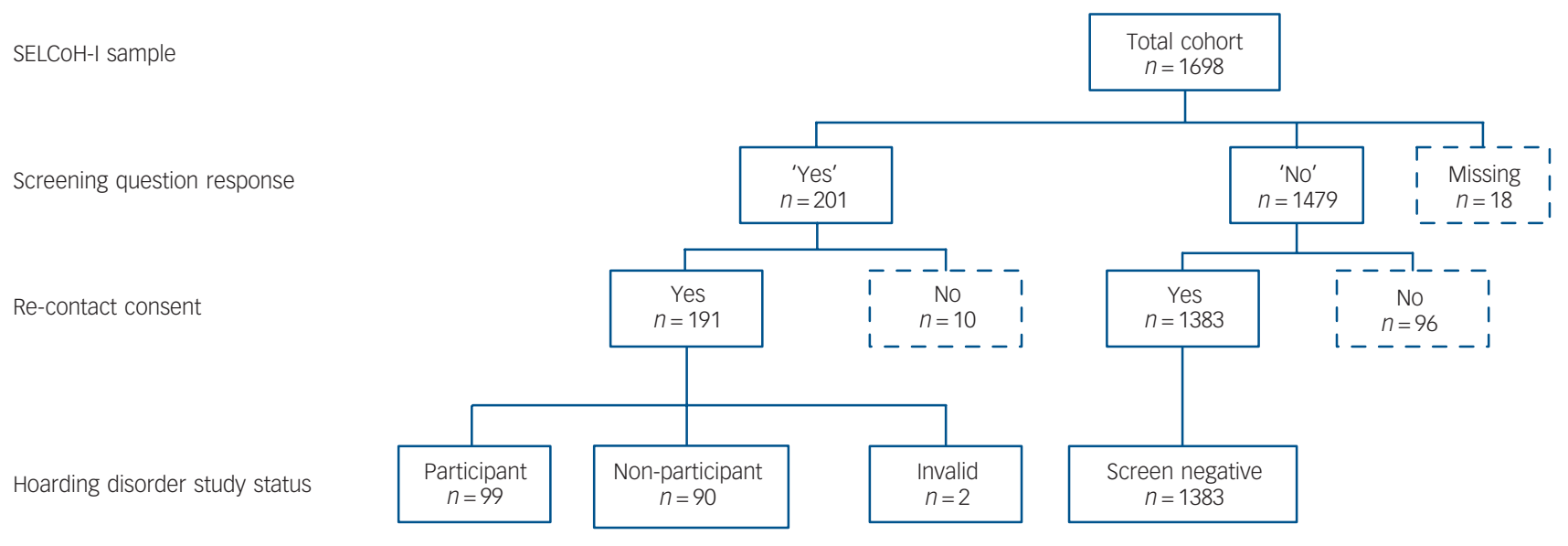

Fig. 1 Participant flowchart.

Of the 191 individuals responding 'yes' to the screening question (12\% SELCoH-II population; 95\% CI 10.5-13.7), 101 were ultimately interviewed for the Hoarding Study. Two of these interviews were deemed invalid (owing to significant language barriers in one case, inability to give informed consent in the other) and omitted from analyses, resulting in 99 contributors to the final participant sample $(51.8 \%$ of the screen-positive/ study-eligible population) (Fig. 1).

Analyses indicated that study-eligible individuals who chose to participate $(n=99)$ did not differ significantly from eligible nonparticipants $(n=90)$ on key variables including age, gender, education, perceived health and presence of common mental disorders (Table 1).

\section{Prevalence of hoarding disorder and sociodemographic features}

Among Hoarding Study participants $(n=99), 19(19.2 \%)$ met criteria for hoarding disorder and were considered cases in subsequent analyses. A further 8 participants were classified as subclinical $(8.1 \%)$ and the remainder as not having hoarding disorder $(n=72 ; 72.8 \%)$. Subclinical individuals were considered 'non-cases' for the remainder of the investigation (total non-cases $n=80 ; 80.8 \%)$. Using these figures, the unweighted prevalence of hoarding disorder in the current population $(n=1482)$ was equivalent to $1.3 \%$ (95\% CI $0.7-1.9)$. The weighted prevalence increased slightly to $1.5 \%$ (95\% CI 0.7-2.2). Among women $(n=837)$, the prevalence of hoarding disorder was $1.2 \%$, with a weighted prevalence of $1.5 \%$ (95\% CI 0.5-2.4), whereas among men $(n=645)$ the unweighted prevalence was $1.4 \%$, with a weighted prevalence of $1.5 \%$ (95\% CI $0.5-2.5$ ).

The endorsement of each hoarding disorder diagnostic criterion, by group, is summarised in Tables 2 and 3, while the demographic and health features of all hoarding disorder cases are summarised in Table 4. Among those with a hoarding disorder diagnosis, it should be noted that one participant presented with comorbid OCD, and hoarding disorder was excluded in an additional two individuals presenting with OCD symptoms.

\section{Sensitivity of the prevalence estimates}

For all individuals responding 'no' at the screening stage $(n=1383)$, SELCoH-I home environment notes were examined 
Table 1 Basic demographic and health features of eligible participants and eligible non-participants

\begin{tabular}{|c|c|c|c|c|}
\hline & $\begin{array}{l}\text { Non-participants } \\
\qquad(n=90)\end{array}$ & $\begin{array}{l}\text { Participants } \\
\qquad(n=99)\end{array}$ & Statistic & $P$ \\
\hline Age, years: mean (s.d.) & $41.78(17.91)$ & $44.28(17.42)$ & $-1.040^{\mathrm{a}}$ & 0.298 \\
\hline Gender, $n(\%)$ & & & $0.200^{\mathrm{b}}$ & 0.655 \\
\hline Male & $38(42.2)$ & 45 (45.5) & & \\
\hline Female & $52(57.8)$ & $54(54.5)$ & & \\
\hline Ethnicity, $n$ (\%) & & & $2.389^{b}$ & 0.303 \\
\hline White & $51(56.7)$ & $64(64.6)$ & & \\
\hline Other & 39 (43.3) & $34(34.4)$ & & \\
\hline Unknown & $0(0)$ & $1(1)$ & & \\
\hline Educational attainment, ${ }^{\mathrm{c}} \mathrm{n}(\%)$ & & & $3.482^{b}$ & 0.062 \\
\hline No qualifications/GCSEs only & $41(45.6)$ & $32(32.3)$ & & \\
\hline$\geqslant$ A-levels & $49(54.4)$ & $67(67.7)$ & & \\
\hline Current occupational status, $n$ (\%) & & & $0.653^{b}$ & 0.419 \\
\hline Full time/part-time/student & $57(63.3)$ & $57(57.6)$ & & \\
\hline Unemployed/retired/disabled & $33(36.7)$ & $42(42.4)$ & & \\
\hline Marital status, $n(\%)$ & & & $2.895^{\mathrm{b}}$ & 0.408 \\
\hline Single & $37(41.1)$ & 34 (34.3) & & \\
\hline Married/cohabiting & $41(45.6)$ & $43(43.4)$ & & \\
\hline Divorced & $9(10)$ & $18(18.2)$ & & \\
\hline Widowed & $3(3.3)$ & $4(4.1)$ & & \\
\hline Self-reported health, $n$ (\%) & & & $5.496^{\mathrm{b}}$ & 0.064 \\
\hline Excellent/very good & $41(45.5)$ & $31(31.3)$ & & \\
\hline Good & $24(26.7)$ & $41(41.4)$ & & \\
\hline Fair/poor & $25(27.8)$ & $27(27.3)$ & & \\
\hline Common mental disorder, $n$ (\%) & & & 3.228 & 0.072 \\
\hline No & $58(64.4)$ & $51(51.5)$ & & \\
\hline Yes & $32(35.6)$ & $48(48.5)$ & & \\
\hline \multicolumn{5}{|c|}{$\begin{array}{l}\text { a. Z statistic. } \\
\text { b. Chi-squared test. } \\
\text { c. UK education qualifications: GCSE (General Certificate of Secondary Education), received as part of secondary education in the UK (typically age 16); A-levels (General Certificate } \\
\text { of Education Advanced Level), received on completion of pre-university education (typically age 18); degree level indicates receipt of (at minimum) a university diploma. }\end{array}$} \\
\hline
\end{tabular}

for language indicative of potential hoarding behaviour (e.g. extremely cluttered). This process indicated an inconsistency between participants' responses to the screening question and the actual state of their accommodation in 28 cases $(2.02 \%$ of 'screen negative' sample; see online Table DS1). Cases where clutter was attributed to a temporary event, such as ongoing renovation work, were not included in this estimate.

Further examination of these environment ratings and the corresponding hoarding disorder status, for all Hoarding Study participants $(n=99)$, indicated an agreement rate of $77.9 \%$ $(\kappa=0.41 ;$ s.e. $=0.1 ; \quad P<0.001)$. Overall, these lay reports were more likely to indicate hoarding symptoms as present (divergences in this direction $n=16 ; 16.2 \%$ ) than to contradict their presence (divergences in this direction $n=6 ; 6.1 \%$ ).

Regarding the potential impact of the insight bias on the prevalence estimate: if we are conservative and consider the proportion of cases in our interviewed sample (19 of 99; $19.19 \%$ ) and apply this proportion to the 28 potential false negatives, we would expect to garner an additional 5 cases. This increase would alter the raw prevalence estimate to $1.62 \%$ (95\% CI 1.04-2.40).

\section{Comparison of hoarding disorder cases and non-cases}

\section{Sociodemographic features}

The demographic features of individuals with hoarding disorder $(n=19)$ and participants without the disorder $(n=80)$ were compared with all individuals responding 'no' to the SELCoH-I hoarding screener $(n=1383)$. Results of these comparisons (Table 4) indicated significant differences across groups, with individuals with hoarding disorder being overall older and significantly more likely to be in financial difficulty. Differences in marital status were also evident, with a higher percentage of individuals with hoarding disorder being divorced or widowed, and a lower proportion being married or cohabiting.

\section{Physical and mental health features}

Compared with participants without hoarding disorder $(n=78)$ and screen-negative individuals $(n=1383)$, those with hoarding disorder were more likely to report poor health issues and to feel that a current illness was limiting their work and/or social activities. Current drug use tended (non-significantly) to be higher among individuals with hoarding disorder, with other health behaviours (e.g. smoking, problematic drinking) being largely equivalent across groups (Table 5; see online Table DS2 for full data).

Regarding mental health variables, differences were particularly evident between the hoarding disorder and 'screen negative' groups. The former showed significantly more frequent reports of common mental disorders, somatic symptoms, fatigue, current depression, current anxiety, lifetime PTSD, personality disorder and psychotic features. These differences were not as pronounced when comparing the hoarding disorder and no hoarding disorder/ subclinical groups, although with the exception of psychotic features the direction of difference remained consistent. Those with hoarding disorder were also most likely to report that their mental health interfered with occupational and social activities.

Finally, although a higher proportion of individuals with hoarding disorder reported seeking help for a mental health problem over their lifetime, compared with control participants, only about a third sought help in the past year.

Comparisons of individuals with hoarding disorder $(n=19)$ with participants without hoarding disorder $(n=80)$ on hoardingassociated measures (Table 3 ) indicated significant differences in 
Table 2 Endorsement of hoarding disorder criteria and specifiers by study group

\begin{tabular}{|c|c|c|c|}
\hline & $\begin{array}{l}\text { No hoarding } \\
\text { disorder } \\
(n=72)\end{array}$ & $\begin{array}{l}\text { Subclinical } \\
\qquad(n=8)\end{array}$ & $\begin{array}{l}\text { Hoarding } \\
\text { disorder } \\
(n=19)\end{array}$ \\
\hline \multicolumn{4}{|l|}{ Criterion, $n$ (\%) } \\
\hline Criterion A & $57(79.2)$ & $8(100)$ & 19 (100) \\
\hline Criterion B & $48(66.7)$ & $8(100)$ & $19(100)$ \\
\hline Criterion C & $2(2.8)$ & $0(0)$ & $19(100)$ \\
\hline Criterion D & $0(0)$ & $7^{\mathrm{a}}(87.5)$ & $19(100)$ \\
\hline Criterion $\mathrm{E}$ & $72(100)$ & $8(100)$ & $19(100)$ \\
\hline Criterion $\mathrm{F}$ & $71^{b}(98.6)$ & $8(100)$ & $19(100)$ \\
\hline \multicolumn{4}{|l|}{ Specifier, $n$ (\%) } \\
\hline Insight (good) & $71(98.6)$ & $8(100)$ & $12(63.2)$ \\
\hline Excessive acquisition & $30(41.7)$ & $5(62.5)$ & $12(63.2)$ \\
\hline \multicolumn{4}{|c|}{$\begin{array}{l}\text { a. One participant in the subclinical group was determined not to meet either criteria } \\
\text { or D, as their age and current living situation (an environment shared with and } \\
\text { managed by their parents) made the identification of these features ambiguous. } \\
\text { b. One case of object accumulation was secondary to schizophrenia. However, } \\
\text { this case was further ruled out by earlier criteria as the participant lacked clinically } \\
\text { significant clutter and/or accompanying distress. }\end{array}$} \\
\hline
\end{tabular}

the expected direction, with the hoarding disorder group reporting greater hoarding severity, more problematic clutter and greater levels of squalor in their current accommodations.

\section{Discussion}

This study provides, for the first time since its introduction to DSM-5, an estimate of the population prevalence for hoarding disorder. Our findings indicated an unweighted prevalence of $1.3 \%$ (95\% CI 0.7-1.9), with weightings increasing this estimate to $1.5 \%$ (95\% CI $0.7-2.2$ ). This figure is lower than previously reported estimates of $2-5.8 \%$, which have been based on varying definitions of 'problematic hoarding. ${ }^{6-8,32}$ Like previous studies, we confirmed that hoarding disorder is more prevalent in older adults. ${ }^{6}$ We also found a similar prevalence of hoarding disorder across genders, an unresolved issue in the previous literature with some studies reporting a preponderance of males (e.g. Samuels et $a l^{6}{ }^{6}$ Iervolino $\left.e t a l^{7}\right)$, whereas others have found no gender differences (e.g. Timpano et $a l^{32}$ Fullana et $a l^{33}$ ).

\begin{tabular}{|lcccc|}
\hline Table 3 Endorsement of questionnaire scores by study group & & & \\
& $\begin{array}{c}\text { No hoarding disorder/subclinical } \\
(n=80) \text {, mean (s.d.) }\end{array}$ & $\begin{array}{c}\text { Hoarding disorder } \\
(n=19) \text {, mean (s.d.) }\end{array}$ & $z$ & $P$ \\
\hline Hoarding Rating Scale Self-Report, total & $8.28(5.95)$ & $17.89(7.32)$ & -4.75 & $<0.001$ \\
\hline Clutter Image Rating, average of three rooms & $1.78(0.72)$ & $3.67(1.71)$ & -5.40 & $<0.001$ \\
\hline Compulsive Acquisition Scale, total & $44.06(17.75)$ & $50.42(14.70)$ & -1.92 & 0.055 \\
\hline Home Environment Index, total & $7.03(5.08)$ & $9.47(4.53)$ & -2.27 & 0.023 \\
\hline
\end{tabular}

\begin{tabular}{|c|c|c|c|c|c|}
\hline & $\begin{array}{l}\text { Hoarding disorder } \\
\qquad(n=19)\end{array}$ & $\begin{array}{l}\text { No hoarding disorder/ } \\
\text { subclinical }(n=80)\end{array}$ & $\begin{array}{l}\text { Screen negative } \\
\qquad(n=1383)\end{array}$ & Statistic & $P$ \\
\hline Age, years: mean (s.d.) & $48.8(14.89)$ & $43.2(17.89)$ & $39.4(16.58)$ & $10.65^{b}$ & 0.005 \\
\hline Number of rooms in home: mean (interquartile range) & $4(3-5)$ & $4(3-5)$ & $4(3-5)$ & $3.39^{b}$ & 0.183 \\
\hline Gender, $n(\%)$ & & & & $0.20^{c}$ & 0.907 \\
\hline Male & $9(47.4)$ & $36(45.0)$ & $600(43.4)$ & & \\
\hline Female & $10(52.6)$ & $44(55.0)$ & $783(56.6)$ & & \\
\hline Ethnicity, $n(\%)$ & & & & $-{ }^{d}$ & 0.388 \\
\hline White & $15(78.9)$ & $49(61.3)$ & $880(63.6)$ & & \\
\hline Other & $4(21.1)$ & $30(37.5)$ & $502(32.3)$ & & \\
\hline Marital status, $n(\%)$ & & & & ${ }^{d}$ & 0.034 \\
\hline Single & $5(26.3)$ & $29(36.3)$ & $550(39.8)$ & & \\
\hline Married/cohabiting & $6(31.6)$ & $37(46.2)$ & $650(47.0)$ & & \\
\hline Divorced & $6(31.6)$ & $12(15.0)$ & $143(10.3)$ & & \\
\hline Widowed & $2(10.5)$ & $2(2.5)$ & $40(2.9)$ & & \\
\hline Educational attainment, ${ }^{\mathrm{e}} n(\%)$ & & & & 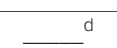 & 0.590 \\
\hline No qualification & $2(10.5)$ & $7(8.8)$ & $176(12.7)$ & & \\
\hline GCSE & $5(26.3)$ & $18(22.5)$ & 257 (18.6) & & \\
\hline A-levels & $4(21.1)$ & $27(33.7)$ & $343(24.8)$ & & \\
\hline Degree level & $8(42.1)$ & $28(35.0)$ & $593(42.9)$ & & \\
\hline Employed/studying, $n$ (\%) & & & & $1.26^{\mathrm{C}}$ & 0.869 \\
\hline Yes & $12(63.2)$ & $55(68.8)$ & $936(67.7)$ & & \\
\hline No & $7(36.8)$ & $25(31.2)$ & $433(31.3)$ & & \\
\hline Financial debt, $n(\%)$ & & & & $23.28^{\mathrm{C}}$ & $<0.001$ \\
\hline Yes & $9(47.4)$ & $15(18.8)$ & $227(16.4)$ & & \\
\hline No & $10(52.6)$ & $61(76.2)$ & $1142(82.6)$ & & \\
\hline Receives benefits, $n(\%)$ & & & & $11.07^{c}$ & 0.026 \\
\hline Yes & $9(47.4)$ & $29(36.3)$ & $336(24.3)$ & & \\
\hline No & $10(52.6)$ & $51(63.7)$ & $1040(75.2)$ & & \\
\hline \multicolumn{6}{|c|}{$\begin{array}{l}\text { a. Frequencies may not sum to } 100 \% \text { due to missing values } \\
\text { b. H statistic. } \\
\text { c. Chi-squared test. } \\
\text { d. Fisher's exact test used. } \\
\text { e. UK education qualifications: GCSE (General Certificate of Secondary Education), received as part of secondary education in the UK (typically age 16); A-levels (General Certificate } \\
\text { of Education Advanced Level), received on completion of pre-university education (typically age 18); degree level indicates receipt of (at minimum) a university diploma. }\end{array}$} \\
\hline
\end{tabular}


Our face-to-face evaluations of hoarding disorder, in participants homes and in the form of a DSM-5-based diagnostic interview, represent significant methodological improvements relative to prior work. The importance of in-home evaluations in particular has been emphasised in several studies to date. ${ }^{1,34}$ Such work has highlighted the uniquely visual nature of hoarding disorder and indicated that the assessment of the clutter criterion is optimal when evaluators are permitted access to the person's home. The careful evaluation of this criterion is particularly important as, among individuals who self-identify with hoarding difficulties, research suggests that it is often endorsement of the clutter criterion (or lack thereof) that establishes the presence of true hoarding disorder. This finding is supported by the current investigation, in which no subclinical and only two $(2.8 \%)$ individuals with no hoarding disorder were determined to have clinically significant clutter, whereas a minimum $66.7 \%$ were found to endorse each of the remaining hoarding disorder criteria. The unique effort of the current study to adequately assess this key feature does, consequently, lend additional confidence to the diagnoses assigned.

Our demographic findings confirmed prior characterisations of individuals with hoarding disorder as older, more frequently unemployed, and more often unmarried, separated or divorced than comparator groups. ${ }^{1,2}$ This investigation, which highlights the financial challenges facing this population (e.g. delayed repayments, benefits), also complements prior studies suggesting that individuals with hoarding issues face economic difficulty. ${ }^{2}$ It is likely that such findings reflect additional consequences of the functional decline inherent to this kind of progressive psychiatric disorder. However, it is worth considering that the ubiquity of 'excessive acquisition' in this and the majority of hoarding disorder samples ${ }^{32,35}$ may play a particular role in the development of these difficulties.

Regarding health features, our data also indicate that hoarding disorder is associated with poorer perceived physical health, reduced occupational and social functionality, as well as increased reports of psychiatric comorbidity. In combination, these findings indicate that this population is experiencing impairments across multiple spheres of daily life. Despite these impairments, it was found that only a third of individuals with hoarding disorder had sought professional assistance for a mental health issue in the preceding year. The cognitions underlying this seeming avoidance remain unclear and would benefit from an investigation

\begin{tabular}{|c|c|c|c|c|c|}
\hline & $\begin{array}{l}\text { Hoarding disorder } \\
\qquad(n=19)\end{array}$ & $\begin{array}{l}\text { No hoarding disorder/ } \\
\text { subclinical }(n=80)\end{array}$ & $\begin{array}{l}\text { Screen negative } \\
\qquad(n=1383)\end{array}$ & Statistic & $P$ \\
\hline \multicolumn{6}{|l|}{ Physical health features, ${ }^{\mathrm{b}} \mathrm{n}(\%)$} \\
\hline Self-reported health & & & & ${ }^{\mathrm{c}}$ & 0.001 \\
\hline Excellent/very good & $2(10.5)$ & $29(36.3)$ & $700(50.6)$ & & \\
\hline Good & $12(63.2)$ & $29(36.3)$ & 458 (33.1) & & \\
\hline Fair/poor & $5(26.3)$ & $22(27.4)$ & $223(16.1)$ & & \\
\hline Smoking & & & & $ـ^{\mathrm{c}}$ & 0.174 \\
\hline Never & $5(26.3)$ & $22(27.4)$ & $408(29.5)$ & & \\
\hline Current & $8(42.1)$ & $23(28.8)$ & $344(24.8)$ & & \\
\hline Past & $5(26.3)$ & $27(33.8)$ & $373(27.0)$ & & \\
\hline Occasional & $1(5.3)$ & $8(10)$ & $258(18.7)$ & & \\
\hline Drugs (current) & & & & 9.40 & 0.052 \\
\hline Yes & $5(26.3)$ & $18(22.5)$ & $174(12.6)$ & & \\
\hline No & $14(73.7)$ & $62(77.5)$ & $1207(87.3)$ & & \\
\hline Hazardous alcohol use & & & & 6.11 & 0.191 \\
\hline Yes & $5(26.3)$ & $22(27.4)$ & $278(20.1)$ & & \\
\hline No & $14(73.7)$ & $57(71.3)$ & $1102(79.7)$ & & \\
\hline Illness limits activity & & & & 18.21 & 0.006 \\
\hline Yes & $9(47.4)$ & $23(28.8)$ & $236(17.1)$ & & \\
\hline No & $10(52.6)$ & $57(71.2)$ & $1145(82.8)$ & & \\
\hline \multicolumn{6}{|l|}{ Mental health features } \\
\hline CIS-R score, mean (s.d.) & $13.6(11.37)$ & 13.5 (11.31) & $6.7(7.82)$ & $43.23^{\mathrm{d}}$ & $<0.001$ \\
\hline Fatigue (current), $n$ (\%) & & & & ${ }^{\mathrm{c}}$ & 0.002 \\
\hline Yes & $5(26.3)$ & $16(20)$ & $122(8.8)$ & & \\
\hline No & $13(68.4)$ & $63(78.8)$ & $1210(87.4)$ & & \\
\hline PTSD (lifetime), $n$ (\%) & & & & $\mathrm{C}^{\mathrm{c}}$ & 0.148 \\
\hline Yes & $3(15.8)$ & $6(7.5)$ & $64(4.6)$ & & \\
\hline No & $16(84.2)$ & $74(92.5)$ & $1313(94.9)$ & & \\
\hline Personality disorder (lifetime), $n$ (\%) & & & & ${ }^{\mathrm{c}}$ & 0.003 \\
\hline Yes & $5(26.3)$ & $20(25)$ & $178(12.7)$ & & \\
\hline No & $13(68.4)$ & $59(73.8)$ & 1191 (85.2) & & \\
\hline Depression (current), $n$ (\%) & & & & $\ldots^{\mathrm{c}}$ & 0.001 \\
\hline Yes & $5(26.3)$ & $20(25)$ & $146(10.6)$ & & \\
\hline No & $14(73.7)$ & $60(75)$ & $1232(89.4)$ & & \\
\hline Anxiety (current), $n$ (\%) & & & & $40.41^{b}$ & $<0.001$ \\
\hline Yes & $7(36.8)$ & 26 (32.5) & $157(11.4)$ & & \\
\hline No & $12(63.2)$ & 54 (67.5) & $1221(88.6)$ & & \\
\hline Psychotic features (past year), $n$ (\%) & & & & ${ }^{\mathrm{c}}$ & $<0.001$ \\
\hline Yes & $5(26.3)$ & $23(28.8)$ & $172(12.4)$ & & \\
\hline No & $14(73.7)$ & $57(71.2)$ & $1211(87.6)$ & & \\
\hline
\end{tabular}


into perceived barriers or consequences, particularly given that the majority of this population (62\%) reported the use of mental healthcare services during their lifetime.

\section{Limitations and implications}

Although we strove to ensure the thorough assessment of our study participants, it should be noted that our use of a screening question to narrow the pool of interviewees did introduce the potential for population bias, particularly as a function of insight. Research using family informants indicates that up to half of individuals with hoarding symptoms exhibit poor or absent insight regarding the consequences of their symptoms. ${ }^{36}$ The majority of our diagnosed cases were classed as good insight, suggesting that some individuals with lower insight may have incorrectly characterised their saving behaviours at the screening stage.

Our ability to separately examine the home environment ratings of all SELCoH participants offered an essential check for these concerns and suggested a contradiction between negative screener responses and the state of accommodation in a minimum of 28 'screen-negative' individuals. We suspect that the evaluation of these participants would increase the prevalence of hoarding disorder in the current population. A conservative estimate of this increase would result in a raw prevalence of $1.62 \%(95 \%$ CI $1.04-2.40)$.

The potential impact of our participation rate, on our final prevalence estimate, is also worth noting here. It is clear that a series of factors, such as the time lag between SELCoH study phases and the use of a highly transient urban population, could have posed barriers to participation in the current investigation. This reality is reflected by the majority of non-participants (64\%) who, despite consenting to future contact, could not be reached at any stage of SELCoH-II. Of those who could be contacted, a further $10 \%$ reported changes in location $(n=8)$ and health $(n=1)$ that precluded their study involvement. These individuals were, ultimately, not seen for interview and their diagnostic status remains unclear. However, each of these individuals endorsed this study's screening question and, as our results show, resembled their participant counterparts across the assessed demographic characteristics. We might, therefore, hypothesise that interviews with these individuals $(n=90)$ would reveal a similar proportion of cases as were observed in our participant population (19\%). Were this assumption upheld, the impact would be a considerable increase in the disorder's raw prevalence $(1.5 \%$ v. $2.4 \%)$.

Similarly, the targeted, door-to-door approach used in the initial SELCoH recruitment may have resulted in underdetection of potential hoarding disorder cases. Research has demonstrated a range of issues facing those with significant hoarding behaviours, including the threat of eviction, forced clearings and the removal of dependents. ${ }^{2,37}$ Combined with the portrait of social isolation that has emerged in this population, it is likely that the solicitation of participation by unknown persons, on the individual's doorsteps, would be met with significant avoidance or refusal to participate in the study. Taken together, these factors suggest that the prevalence estimate provided here may be best viewed as a lower bound of the true hoarding disorder prevalence. Future work would benefit from the focused evaluation of challenging cases (e.g. low-insight; at-risk), as access to these populations would provide a valuable companion to the current prevalence estimate. The solicitation of cases from secondary sources (e.g. Social Services, housing associations) may offer an avenue of access to these individuals.

The methods for evaluating psychiatric comorbidities in the current study also present a limitation. Although the screening tools utilized for the SELCoH-I assessments represent widely used and validated epidemiological measures, and although their structured questions are ideal for use by lay interviewers, future work would benefit from the inclusion of clinician-administered, psychiatric diagnostic interviews. We were at least able to confidently rule out OCD, the most significant differential diagnosis in hoarding disorder due to historical links between the two conditions.

Finally, the size of our sample did impose some analytic constraints - restricting, in particular, our ability to carry out further analyses within our hoarding disorder group (e.g. by gender, age band or ethnicity). As such factors may have bearing on both detection and treatment, a clear need for investment in more large-scale, population-based, investigations remains.

In sum, hoarding disorder is present in approximately $1.5 \%$ of the South East London population, affects people of both genders and is associated with substantial adversity. The reported prevalence estimates may be an underestimate of the true prevalence of the disorder and further research is needed, particularly among individuals displaying poor insight into their difficulties. It also remains to be seen whether the results are generalisable to other communities and cultures.

Ashley E. Nordsletten, MSC, Department of Psychosis Studies, King's College London, Institute of Psychiatry, London, UK; Abraham Reichenberg, PhD, Department of Psychosis Studies, King's College London, Institute of Psychiatry, London, UK, and Departments of Psychiatry and Preventive Medicine, Seaver Center for Autism Research and Treatment and Friedman Brain Institute, Ichan Medical School at Mount Sinai, New York, USA; Stephani L. Hatch, PhD, Lorena Fernández de la Cruz, PhD, Alberto Pertusa, MD, PhD, Matthew Hotopf, MRCPsych, PhD, David Mataix-Cols, PhD, Department of Psychosis Studies, King's College London, Institute of Psychiatry, London, UK

Correspondence: Ashley E. Nordsletten, Department of Psychosis Studies, King's College London, Institute of Psychiatry, PO 69, De Crespigny Park, London SE5 8AF, UK. Email: ashley.keller23@googlemail.com

First received 5 Apr 2013, final revision 4 Jul 2013, accepted 5 Sep 2013

\section{Funding}

A.R., S.L.H. and M.H. receive salary support from the National Institute for Health Research (NIHR) Mental Health Biomedical Research Centre at South London and Maudsley NHS Foundation Trust and King's College London. The views expressed are those of the authors and not necessarily those of the NIHR, the National Health Service or the Department of Health. The SELCOH study was supported by the Biomedical Research Nucleus data management and informatics facility at South London and Maudsley NHS Foundation Trust, which is funded by the NIHR Mental Health Biomedical Research Centre at South London and Maudsley NHS Foundation Trust and King's College London, and a joint infrastructure grant from Guy's and St Thomas' Charity and the Maudsley Charity. These funders had go inomer Gu's and St Thoms' Charity and the Mauds ey chanty. These funders had no involvement in study design, data collection, analysis, or the decision to submit for publication.

\section{Acknowledgements}

The authors thank Drs Marta Llorens Capdevila and David Nordsletten, along with the members of the SELCOH team, for their assistance in the preparation of this manuscript.

\section{References}

1 Mataix-Cols D, Billotti D, Fernández de la Cruz L, Nordsletten AE. The London field trial for hoarding disorder. Psychol Med 2013; 43: 837-48.

2 Tolin DF, Frost RO, Steketee G, Fitch KE. Family burden of compulsive hoarding: results of an internet survey. Behav Res Ther 2008; 46: 334-44.

3 Wilbram M, Kellett S, Beail N. Compulsive hoarding: a qualitative investigation of partner and carer perspectives. Br J Clin Psychol 2008; 47(Pt 1): 59-73.

4 Tolin DF, Frost RO, Steketee G, Gray KD, Fitch KE. The economic and social burden of compulsive hoarding. Psychiatry Res 2008; 160: 200-11.

5 Saxena S, Ayers CR, Maidment KM, Vapnik T, wetherell JL, Bystritsky A. Quality of life and functional impairment in compulsive hoarding. J Psychiatr Res 2011; 45: 475-80. 
6 Samuels JF, Bienvenu OJ, Grados MA, Cullen B, Riddle MA, Liang KY, et al. Prevalence and correlates of hoarding behavior in a community-based sample. Behav Res Ther 2008; 46: 836-44.

7 Iervolino AC, Perroud N, Fullana MA, Guipponi M, Cherkas L, Collier DA, et al. Prevalence and heritability of compulsive hoarding: a twin study. Am J Psychiatry 2009; 166: 1156-61.

8 Mueller A, Mitchell JE, Crosby RD, Glaesmer H, de Zwaan M. The prevalence of compulsive hoarding and its association with compulsive buying in a German population-based sample. Behav Res Ther 2009; 47: 705-9.

9 Pertusa A, Frost RO, Fullana MA, Samuels J, Steketee G, Tolin D, et al. Refining the diagnostic boundaries of compulsive hoarding: a critical review. Clin Psychol Rev 2010; 30: 371-86.

10 Frost RO, Steketee G, Tolin DF. Diagnosis and assessment of hoarding disorder. Annu Rev Clin Psychol 2012; 8: 219-42.

11 Hatch SL, Frissa S, Verdecchia M, Stewart R, Fear NT, Reichenberg A, et al Identifying socio-demographic and socioeconomic determinants of health inequalities in a diverse London community: the South East London Community Health (SELCOH) study. BMC Public Health 2011; 11: 861

12 Fernández de la Cruz L, Nordsletten AE, Billotti D, Mataix-Cols D. Photograph-aided assessment of clutter in hoarding disorder: is a picture worth a thousand words? Depress Anxiety 2013; 30: 61-6.

13 Leckman JF, Sholomskas D, Thompson WD, Belanger A, Weissman MM. Best estimate of lifetime psychiatric diagnosis: a methodological study. Arch Gen Psychiatry 1982; 39: 879-83.

14 Lecrubier $Y$, Sheehan D, Weiller E, Amorim P, Bonora I, Harnett Sheehan K, et al. The Mini International Neuropsychiatric Interview (MINI). A short diagnostic structured interview: reliability and validity according to the CIDI. Eur Psychiatry 1997; 12: 224-31.

15 Sheehan DV, Lecrubier $\mathrm{Y}$, Sheehan $\mathrm{KH}$, Amorim $\mathrm{P}$, Janavs J, Weiller $\mathrm{E}$, et al. The Mini-International Neuropsychiatric Interview (MINI): the development and validation of a structured diagnostic psychiatric interview for DSM-IV and ICD-10. J Clin Psychiatry 1998; 59 (suppl 20): 22-33.

16 Nordsletten AE, Fernandez de la Cruz L, Pertusa A, Reichenberg A, Hatch SL, Mataix-Cols D. The Structured Interview for Hoarding Disorder (SIHD): development, usage and further validation. J Obsess Compuls Relat Disord 2013; 2: 346-50.

17 Frost RO, Steketee G, Tolin DF, Renaud S. Development and validation of the clutter image rating. J Psychopathol Behav Assess 2008; 30: 193-203.

18 Tolin DF, Frost RO, Steketee G. A brief interview for assessing compulsive hoarding: the Hoarding Rating Scale-Interview. Psychiatry Res 2010; 178: 147-52.

19 Frost RO, Steketee G, Williams L. Compulsive buying, compulsive hoarding, and obsessive-compulsive disorder. Behav Ther 2002; 13: 201-14.

20 Rasmussen IL, Steketee GS, Tolin DF, Frost RO, Brown TA. Assessing squalo in hoarding: the Home Environment Index. Commun Ment Health J, in press.

21 Ware Jr J, Kosinski M, Keller SD. A 12-Item Short-Form Health Survey: construction of scales and preliminary tests of reliability and validity. Med Care 1996; 34: 220-33.
22 Babor TR, Higgins-Biddle JC, Saunders JB, Monteiro MG. The Alcohol Use Disorders Identification Test: Guidelines for Use in Primary Care. World Health Organization, 2001.

23 Saunders JB, Aasland OG, Babor TF, de la Fuente JR, Grant M. Development of the Alcohol Use Disorders Identification Test (AUDIT): WHO Collaborative Project on Early Detection of Persons with Harmful Alcohol Consumption-II. Addiction 1993; 88: 791-804.

24 Lewis G, Pelosi AJ, Araya R, Dunn G. Measuring psychiatric disorder in the community: a standardized assessment for use by lay interviewers. Psychol Med 1992; 22: 465-86.

25 World Health Organization. The ICD-10 Classification of Mental and Behavioural Disorders: Clinical Descriptions and Diagnostic Guidelines. WHO, 1992.

26 Bebbington $\mathrm{P}$, Nayani $\mathrm{T}$. The psychosis screening questionnaire. Int J Methods Psychiatr Res 1995; 5: 11-9.

27 Moran $\mathrm{P}$, Leese M, Lee T, Walters $\mathrm{P}$, Thornicroft G, Mann A. Standardised Assessment of Personality - Abbreviated Scale (SAPAS): preliminary validation of a brief screen for personality disorder. Br J Psychiatry 2003; 183: $228-32$.

28 Chalder T, Berelowitz G, Pawlikowska T, Watts L, Wessely S, Wright D, et al. Development of a fatigue scale. J Psychosom Res 1993; 37: 147-53.

29 Kroenke K, Spitzer RL, Williams JB. The PHQ-15: validity of a new measure for evaluating the severity of somatic symptoms. Psychosom Med 2002: 64: $258-66$

30 Prins A, Ouimette P, Kimerling R, Camerond RP, Hugelshofer DS, Shaw-Hegwer J, et al. The primary care PTSD screen (PC-PTSD): development and operating characteristics. Int J Psychiatry Clin Pract 2004; 9: 9-14.

31 Iversen AC, van Staden L, Hughes JH, Browne T, Hull L, Hall J, et al. The prevalence of common mental disorders and PTSD in the UK military: using data from a clinical interview-based study. BMC Psychiatry 2009; 9: 68

32 Timpano KR, Exner C, Glaesmer H, Rief W, Keshaviah A, Brahler E, et al. The epidemiology of the proposed DSM-5 hoarding disorder: exploration of the acquisition specifier, associated features, and distress. J Clin Psychiatry 2011; 72: 780-6.

33 Fullana MA, Vilagut G, Rojas-Farreras S, Mataix-Cols D, de Graaf R, Demyttenaere $\mathrm{K}$, et al. Obsessive-compulsive symptom dimensions in the general population: results from an epidemiological study in six European countries. J Affect Disord 2010; 124: 291-9.

34 Mataix-Cols D, Pertusa A. Annual research review: Hoarding Disorder: Potential benefits and pitfalls of a new mental disorder. J Child Psychol Psychiatry 2012; 53: 608-18.

35 Frost RO, Steketee G, Tolin DF. Comorbidity in hoarding disorder. Depress Anxiety 2011; 28: 876-84.

36 Tolin DF, Fitch KE, Frost RO, Steketee G. Family informants' perceptions of insight in compulsive hoarding. Cognit Ther Res 2010; 34: 69-81.

37 Rodriguez Cl, Herman D, Alcon J, Chen S, Tannen A, Essock S, et al. Prevalence of hoarding disorder in individuals at potential risk of eviction in New York City: a pilot study. J Nerv Ment Dis 2012; 200: 91-4. 